\title{
Genotyping of Cryptosporidium Species and Their Clinical Manifestations in Patients with Renal Transplantation and Human Immunodeficiency Virus Infection
}

\author{
Asmita Dey, ${ }^{1}$ Ujjala Ghoshal, ${ }^{1}$ Vikas Agarwal, ${ }^{2}$ and Uday Chand Ghoshal ${ }^{3}$ \\ ${ }^{1}$ Department of Microbiology, Sanjay Gandhi Postgraduate Institute of Medical Sciences, Lucknow, Uttar Pradesh 226014, India \\ ${ }^{2}$ Department of Immunology, Sanjay Gandhi Postgraduate Institute of Medical Sciences, Lucknow, Uttar Pradesh 226014, India \\ ${ }^{3}$ Department of Gastroenterology, Sanjay Gandhi Postgraduate Institute of Medical Sciences, Lucknow, Uttar Pradesh 226014, India \\ Correspondence should be addressed to Ujjala Ghoshal; ujjalaghoshal@yahoo.co.in
}

Received 14 October 2015; Accepted 27 December 2015

Academic Editor: Nongnuch Vanittanakom

Copyright ( 2016 Asmita Dey et al. This is an open access article distributed under the Creative Commons Attribution License, which permits unrestricted use, distribution, and reproduction in any medium, provided the original work is properly cited.

\begin{abstract}
In the present study we aimed to determine (i) frequency of Cryptosporidium species among patients with renal transplantation (RT) and human immunodeficiency virus (HIV) infection and (ii) relationship of the nature, severity, and duration of symptoms with different species and load of Cryptosporidium. Stool samples from 70 (42 RT and 28 HIV) and 140 immunocompromised patients with and without cryptosporidiosis by modified Kinyoun's staining were subjected to qPCR-melting curve analysis for identification of parasite species. GPCR detected one microscopically negative sample to be positive for cryptosporidiosis. $C$. hominis, C. parvum, and mixed infection were detected in 50/71 (70.4\%), 19/71 (26.8\%), and 2/71 (2.8\%) patients, respectively. Patients with cryptosporidiosis had higher stool frequency (median, IQR: 4, 3-6/d versus 3, 2-4/d; $P=0.017$ ) and watery stool (52/71 [73\%] versus 64/139 [46\%]; $P=0.003$ ). Parasite load (median, IQR: $\log _{10} 6.37$ (5.65-7.12), $\left.\log _{10} 5.81(4.26-6.65) ; P=0.046\right)$ and nausea/vomiting $(29 / 50$ [58\%] versus 5/19 [26\%]; $P=0.032)$ were more frequent with $C$. hominis than with C. parvum infection. Thus, Cryptosporidium spp. (mainly C. hominis) is a common cause of diarrhoea in RT and HIV patients.
\end{abstract}

\section{Introduction}

The coccidian enteric parasite Cryptosporidium spp. is a common cause of gastroenteritis and diarrhoea in man $[1,2]$. It causes severe, voluminous watery diarrhea in immunocompromised patients such as those infected with human immunodeficiency virus (HIV) $[3,4]$. However, there is a paucity of studies on Cryptosporidium spp. among renal transplant (RT) recipients $[5,6]$. Infected patients exhibit varying degrees of clinical manifestations. Some patients have severe symptoms over long duration while others recover in 1-2 weeks after a mild attack. The reasons for such diversity, which might be attributed to different genotypes or species of Cryptosporidium spp., or their varying load or host immunity, have not been adequately investigated so far.

Human cryptosporidiosis is mainly caused by Cryptosporidium hominis and C. parvum, which are responsible for most of the outbreaks of Cryptosporidium described so far.
Other less common species are C. meleagridis, C. cuniculus, $C$. viatorum, C. muris, C. canis, C. felis, C. suis, and C. andersoni [7-13]. C. hominis may cause more severe infection than $C$. parvum and other zoonotic species [7, 14-16]. In contrast, in a study from India, HIV positive patients, persons infected with $C$. parvum and other zoonotic species tended to have fever more frequently than those infected with $C$. hominis [11]. Thus, this variation in clinical manifestations might be due to the different Cryptosporidium species. Genotyping of Cryptosporidium has mainly been studied in patients with HIV infection. Currently there is no study on genotyping of Cryptosporidium spp. among renal transplant recipients. Also, relationship between nature, severity, and duration of the symptoms and different species of Cryptosporidium, among RT recipients, is not known.

An inverse relationship between occurrence of cryptosporidiosis and CD4 $\mathrm{T}$ cell count has been well documented in many studies in patients with AIDS. HIV/AIDS patients 


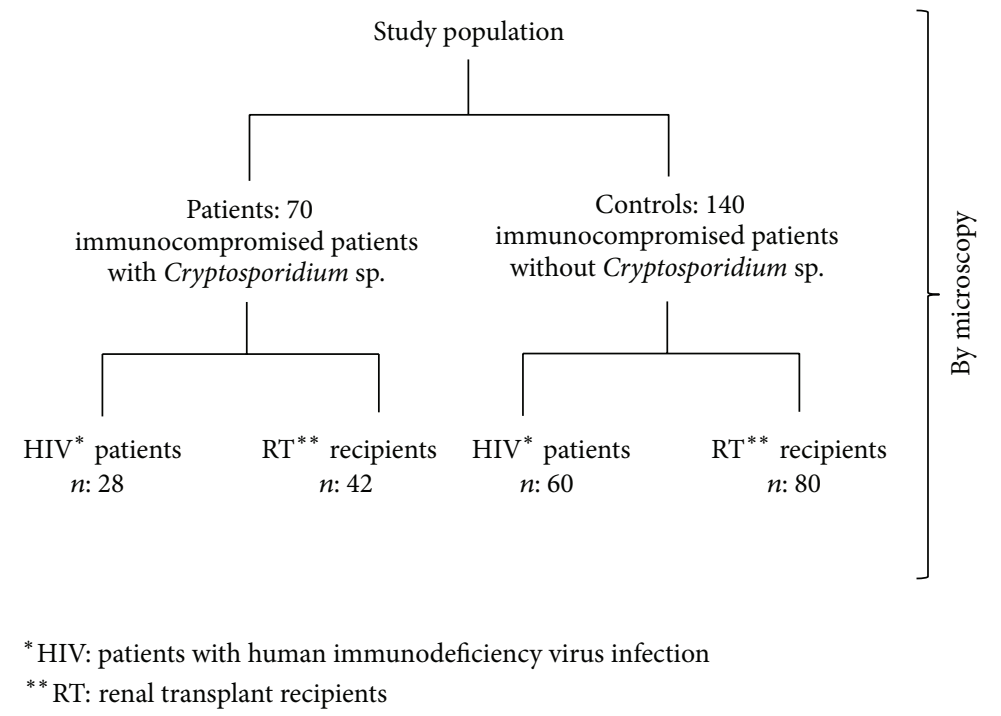

FIGURE 1: Flowchart showing study population and groups in the present study.

having lower CD4 count ( $<200$ cells/cumm) are at higher risk of cryptosporidiosis $[4,17]$, with severe infections below 50 cells/cumm CD4 count $[3,18]$. Such studies are scanty among RT recipients. In fact, the involvement of cell-mediated immunity in cryptosporidiosis has not been investigated in renal transplant recipients.

Microscopy and ELISA are the mainstay for diagnosis of Cryptosporidium spp. but are unable to differentiate among different species. Molecular technique like polymerase chain reaction-restriction fragment length polymorphism (PCRRFLP) is the mainstay for genotyping. However, it is time consuming, requires post-PCR processing, and is prone to cross-contamination and false-positive results [19]. Real-time quantitative PCR (qPCR) is a highly sensitive and specific molecular tool which detects Cryptosporidium spp. and quantifies its load. Being a closed tube assay it prevents postPCR contamination and obviates the need of time consuming procedures, like gel electrophoresis. The diagnostic efficacy of qPCR needs evaluation considering lack of adequate data.

Accordingly, we undertook a prospective study to determine (i) frequency of different species of Cryptosporidium infecting immunocompromised patients (HIV and RT patients) by real-time PCR (qPCR) and (ii) relationship of the nature, severity, and duration of the symptoms with different species of Cryptosporidium and their loads.

\section{Materials and Methods}

2.1. Patients. 70 immunocompromised patients ( 42 RT recipients and 28 patients with HIV infection), having Cryptosporidium infection, with and without diarrhoea, attending a tertiary care centre, between 2008 and 2014, were included in this study. Patients with HIV infection were included as per guidelines of National AIDS Control Organization [20]. RT recipients undergoing at least one renal transplantation were recruited. Microscopy was used for detection and qPCR for genetic characterization of Cryptosporidium spp.
Oocyst load was also determined by qPCR. Clinical and laboratory parameters of patients with cryptosporidiosis were compared with 140 immunocompromised controls (60 HIV and 80 RT recipients) without cryptosporidiosis (Figure 1). Data on demographic, clinical, and laboratory parameters were recorded in a standard questionnaire in each patient. The study protocol was approved by Institutional Ethics Committee (Ref. number PGI/PhD/IEC/57/21.10.2011) and it was in accordance with the Helsinki Declaration [21].

2.2. Sample Collection. Three consecutive stool samples from each patient and control were subjected to microscopy and culture. A part of it was stored at $-40^{\circ} \mathrm{C}$ in normal saline for DNA extraction. Blood in EDTA vials was collected from the patients for determining the CD4 count of the patients.

2.3. Sample Processing. Stool samples were subjected to routine microscopy using saline and iodine direct wet mount technique for detection of cysts and trophozoites of parasites. After stool concentration by formal ether concentration technique, acid fast staining (modified Kinyoun's) was used for detection of oocysts of Cryptosporidium spp. Briefly, the smear was incubated in modified Kinyoun's stain for 20 minutes and malachite green was used as counter stain [22]. The stained smears were subjected to light microscopy. Stool samples were also subjected to culture on MacConkey, deoxycholate citrate agar (DCA), and dextrose sorbitol rhamnose agar (DSRA) to exclude other common bacterial agents causing diarrhoea such as Salmonella and Shigella spp. [23].

\subsection{Genetic Characterization of Cryptosporidium spp.}

2.4.1. DNA Extraction. Three consecutive stool samples were pooled into one aliquot from each patient and control and subjected to DNA extraction using QIAamp DNA-stool Mini-kit (QIAGEN Inc., Valencia, CA, USA) according to 


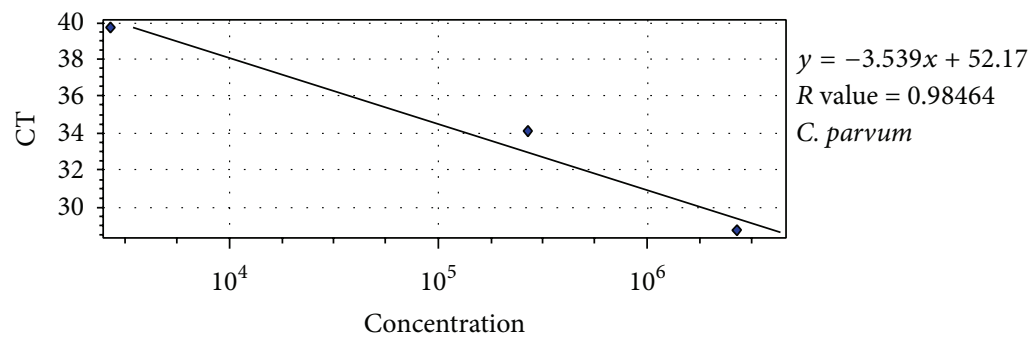

Log concentration of DHFR gene copy number

FIGURE 2: Standard graph (plotted with serially diluted DNA extracted from Cryptosporidium parvum oocyst).

the manufacturer's protocol with some modifications; these included initial washing in $2 \%$ polyvinyl polypyrrolidone (PVPP) dissolved in 1x phosphate buffered saline (PBS) and incubation with stool lysis buffer (Buffer ASL) at $80^{\circ} \mathrm{C}$ for 10 minutes, with occasional stirring in between. DNA was purified and eluted as per manufacturer's instructions.

2.4.2. Polymerase Chain Reaction (PCR). Polymerase chain reaction (PCR) was performed using four primers for the amplification of dihydrofolate reductase (DHFR) gene, one sense and three antisense primers (CINF and CINR, 1R, 2R), aiming to detect Cryptosporidium spp., C. hominis, and $C$. parvum, respectively. The primers used have been described previously [24]. Samples, positive for Cryptosporidium spp. but negative for the two genotypes, were sequenced. Primerpairs CINF and CINR amplified a $575 \mathrm{bp}$ region of the DHFR gene. Primer-pair CINF and 1R amplified a $357 \mathrm{bp}$ region and primer-pair CINF and $2 \mathrm{R}$, a $190 \mathrm{bp}$ region of the DHFR gene. PCR was performed in a total volume of $20 \mu \mathrm{L}$, consisting of $10 \mu \mathrm{L}$ of Green Taq Master Mix (2x), 10 pmoles of forward and reverse primers, and $1 \mu \mathrm{L}$ of template DNA. $100 \mathrm{ng} / \mu \mathrm{L}$ of template DNA from each sample (extracted DNA) was used in PCR reactions. Three sets of reactions were performed with each sample; one with primer set CINF and CINR (for detection of Cryptosporidium spp.), second with primer set CINF and 1R (for detection of C. hominis); third with primer set CINF and $2 \mathrm{R}$ (for detection of C. parvum). PCR conditions were initial denaturation at $95^{\circ} \mathrm{C}$ for $5 \mathrm{~min}$, followed by 40 cycles of denaturation at $94^{\circ} \mathrm{C}$ for $40 \mathrm{sec}$, annealing at $54^{\circ} \mathrm{C}$ for $30 \mathrm{sec}$, and elongation at $72^{\circ} \mathrm{C}$ for $45 \mathrm{sec}$. This was followed by a final elongation step of $72^{\circ} \mathrm{C}$ for $5 \mathrm{~min}$. The PCR products were confirmed by sequencing.

Amplified products were subjected to electrophoresis in $2 \%$ agarose gel. Sequencing of the amplicons was performed using respective species-specific PCR primers. The sequences were compared with those available in the GenBank databases with the BLAST N program.

2.4.3. Real-Time PCR. The amplification was carried out in real-time PCR machine Corbett Research 6000 Q-PCR instrument (Rotor-Gene 6000 software, Sydney, Australia) using the same sets of species-specific primers used in the traditional PCR [24]. The amplification round was carried out in a total volume of $20 \mu \mathrm{L}$ containing $10 \mu \mathrm{L}$ of KAPA-SYBR
FAST Master Mix (Universal qPCR kit; Kapa Biosystems), containing KAPA-SYBR DNA Polymerase (an engineered version of Taq DNA Polymerase designed specifically for realtime PCR, SYBR Green I dye and optimized magnesium chloride concentration). Template DNA (having a concentration of $100 \mathrm{ng} / \mathrm{mL}$ per sample) was added. PCR conditions were as follows: initial denaturation at $95^{\circ} \mathrm{C}$ for $10 \mathrm{~min}, 40$ cycles at $95^{\circ} \mathrm{C}$ for $45 \mathrm{sec}$, then annealing at $54^{\circ} \mathrm{C}$ for $60 \mathrm{sec}$, and extension at $72^{\circ} \mathrm{C}$ for $40 \mathrm{sec}$. Fluorescence data were collected in the extension step. For meting curve analysis (MCA), after completion of last PCR cycle, a quick denaturation was performed at $95^{\circ} \mathrm{C}$ for $1 \mathrm{sec}$, followed by a $30 \mathrm{sec}$ annealing step at $45^{\circ} \mathrm{C}$ with a slow ramp $\left(0.2^{\circ} \mathrm{C} / \mathrm{sec}\right)$ up to $80^{\circ} \mathrm{C}$. Reaction mixture without template DNA was used as negative control.

2.4.4. Standard Graph. Standard graph was plotted with DNA extracted from purified Cryptosporidium parvum oocyst, commercially purchased from The University of Arizona, USA. Oocysts (concentration of $5 \times 10^{7}$ oocysts $/ \mathrm{mL}$ in antibiotic solution) were subjected to DNA extraction by previously mentioned protocol using the QIAamp DNA Mini Kit (QIAGEN Inc., Valencia, CA, USA) [25, 26]. Standard graph was generated via serial dilution of oocyst stock $\left(5 \times 10^{7}\right.$ oocysts $/ \mathrm{mL}$ ) to 5 -fold (corresponding to approximately $10^{7}$ to $10^{3}$ oocysts/mL/dilution). The DHFR gene copies $/ \mu \mathrm{L}$ corresponded approximately to four times the oocysts/dilution due to the presence of single-copy of this gene/sporozoite or 4 copies/oocyst, as one oocyst consists of 4 sporozoites. DNA was extracted from each serial dilution and $100 \mathrm{ng} / \mu \mathrm{L}$ of the extracted DNA was subjected to qPCR using primers specific for C. parvum to estimate the DHFR gene copy number of each serially diluted DNA and thus to construct the standard graph (Figure 2).

2.5. Data Analysis. Nonparametric and parametric continuous variables were analysed by Mann-Whitney $U$ test and unpaired $t$-test, respectively. Categorical variables were analysed by Chi-square test. The values of equivalent oocyst concentrations (parasite load) were transformed into $\log _{10}$ and presented as median and interquartile range (IQR). $P$ values $<0.05$ were considered significant. All the statistical analyses were performed using Statistical Package for the Social Sciences (SPSS 15, Inc., Chicago, IL, USA). 
TABLE 1: Demographic and clinical parameters of immunocompromised patients with and without infection with Cryptosporidium spp.

\begin{tabular}{|c|c|c|c|}
\hline & $\begin{array}{c}\text { Patients with } \\
\text { Cryptosporidium infection } \\
(n=71)\end{array}$ & $\begin{array}{l}\text { Patients without } \\
\text { Cryptosporidium infection } \\
(n=139)\end{array}$ & $P$ value \\
\hline Age (mean, $\left.\mathrm{SD}^{*}\right)$ & $39(13)$ & $39(11)$ & NS \\
\hline Gender (male) & $58 / 71(81.7 \%)$ & $115 / 139(82.7 \%)$ & 0.94 \\
\hline Duration of diarrhoea in days (median, IQR ${ }^{* *}$ ) & $16(3,41)$ & $15(7,60)$ & 0.66 \\
\hline Diarrhoea & $59 / 71(83 \%)$ & $84 / 139(60.4 \%)$ & 0.0014 \\
\hline Watery stool & $52 / 71(73 \%)$ & $64 / 139(46 \%)$ & 0.0003 \\
\hline Daily stool frequency (median, IQR**) & $4(3,6)$ & $3(2,4)$ & 0.017 \\
\hline Fever & $34 / 71(48 \%)$ & $65 / 139(46.7 \%)$ & 0.96 \\
\hline Cough & $18 / 71(26 \%)$ & $41 / 139(29.5 \%)$ & 0.70 \\
\hline Nausea, vomiting & $34 / 71(49 \%)$ & $59 / 139(42.4 \%)$ & 0.38 \\
\hline Abdominal pain & $29 / 71(41 \%)$ & $56 / 139(40.3 \%)$ & 0.88 \\
\hline Drinking water (unfiltered) & $9 / 41(22 \%)$ & $28 / 113(25 \%)$ & 0.717 \\
\hline
\end{tabular}

(SD: Standard deviation, IQR: interquartile range and NS: not significant; Data of drinking water was available for only 41 patients with Cryptosporidium infection and 113 patients without).

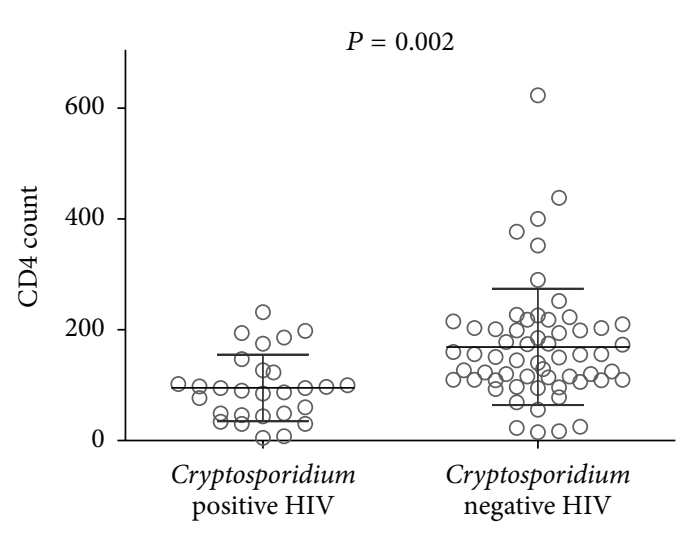

(a)

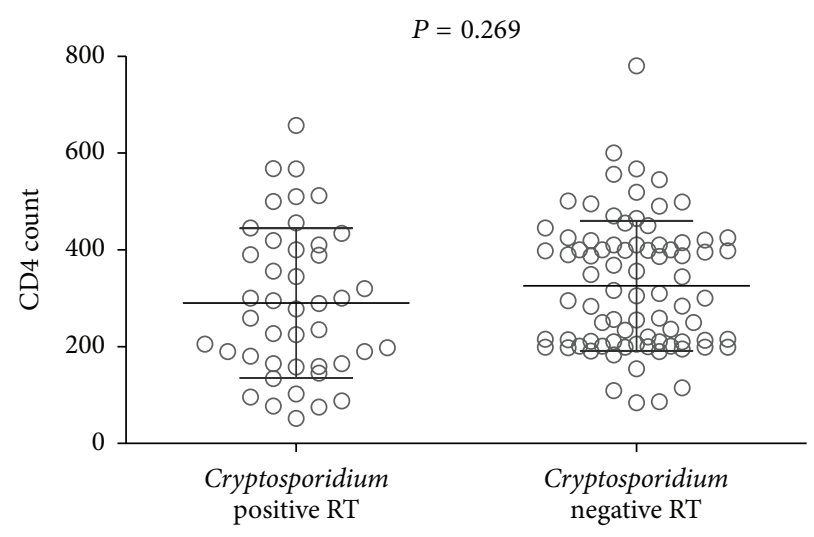

(b)

FIGURE 3: Comparison of CD4 counts of HIV patients with and without cryptosporidiosis; (b): comparison of CD4 counts of RT patients with and without cryptosporidiosis. The bar represents the average. Unpaired Student's $t$-test was used for comparison between groups. $P$ value $<0.05$ was considered as significant. Values given in text (Section 3.1).

\section{Results}

3.1. Demographic, Clinical, and Laboratory Parameters of Patients and Controls. 70 immunocompromised patients were positive for Cryptosporidium spp. by both microscopy and qPCR and one by qPCR alone. Though the oocyst load in the stool of this microscopically negative RT recipient, initially included in the immunocompromised control group, was comparatively lower, being $\log _{10} 6.65$ equivalent oocyst concentration, he was considered as infected. Patients with other parasitic infestation and enteropathogenic bacteria were excluded from analysis. The demographic and clinical parameters of the 71 patients with cryptosporidiosis and 139 immunocompromised controls are shown in Table 1. Cryptosporidiosis was associated with diarrhoea, increased stool frequency, and watery stool (Table 1).

Immunocompromised (both HIV and RT) patients with cryptosporidiosis had lower CD4 count than noninfected ones (mean \pm SD: $214 \pm 162$ cells/cumm versus $260 \pm$ 144 cells/cumm, $P=0.041)$. CD4 count of patients with HIV infection was lower than patients with RT $(145 \pm 10.6$ cells/cumm versus $313 \pm 12.7$ cells/cumm, $P=0.004)$. CD4 count of HIV-infected patients with cryptosporidiosis was lower than those without $(95 \pm 11.3$ cells/cumm versus $169 \pm$ 13.7 cells/cumm, $P=0.002$ ) (Figure 3 ). In contrast, CD4 counts of RT patients, with and without cryptosporidiosis, were comparable $(290 \pm 23.6$ cells/cumm versus $326 \pm 15$ cells/cumm, $P=0.269$ ) (Figure 3 ). Moreover, CD4 count of HIV-infected patients with cryptosporidiosis was lower than that of Cryptosporidium infected RT patients $(223 \pm 23$ cells/cumm versus $260 \pm 12.3$ cells/cumm, $P=0.09$ ); neutrophil count in RT patients with cryptosporidiosis tended to be lower than that in Cryptosporidium infected HIV patients $(67 \pm 10.5$ cells $/$ cumm versus $72 \pm 14$ cells $/$ cumm, $P=0.08)$.

The RT recipients with cryptosporidiosis more often received triple immunosuppressive drugs than those without, 


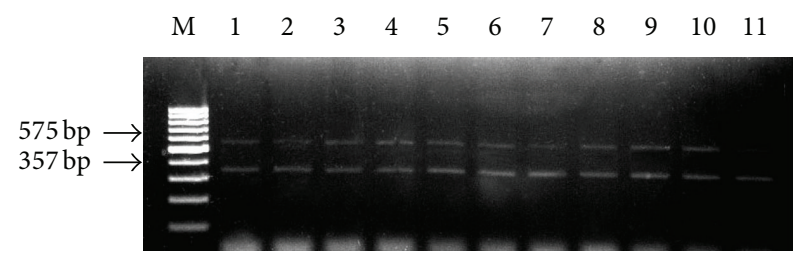

(a)

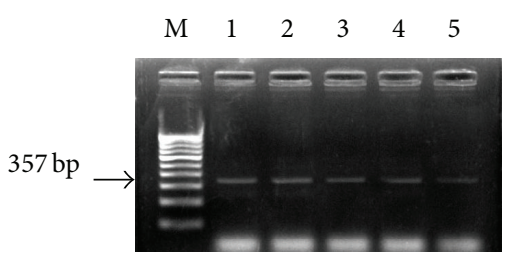

(b)

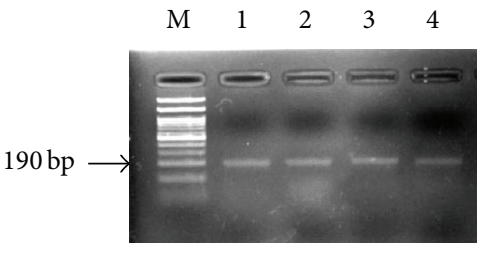

(c)

FIGURE 4: (a) Lane 1: multiplex polymerase chain reaction (PCR) of C. hominis positive control (showing bands for both Cryptosporidium spp. [575 bp] and C. hominis [357 bp]); Lanes 2-11: multiplex PCR of samples positive for C. hominis; (b) Lanes 1-5: PCR of samples positive for C. hominis (357 bp); (c) Lanes 1-4: PCR of samples positive for C. parvum. In all figures, M: $100 \mathrm{bp}$ molecular marker.

TABLE 2: Demographic and clinical parameters between patients infected with C. hominis and C. parvum.

\begin{tabular}{|c|c|c|c|}
\hline & $\begin{array}{l}\text { Patients with C. hominis infection } \\
\qquad(50)\end{array}$ & $\begin{array}{l}\text { Patients with C. parvum infection } \\
\text { (19) }\end{array}$ & $P$ value \\
\hline Age $($ mean $\pm \mathrm{SD})$ in years & $40 \pm 13$ & $33.6 \pm 13$ & 0.43 \\
\hline Gender (males) & $41 / 50(82 \%)$ & $16 / 19(84.2 \%)$ & 0.8 \\
\hline Melting curve $($ mean $\pm \mathrm{SD}){ }^{\circ} \mathrm{C}$ & $74.8 \pm 1.64^{\circ} \mathrm{C}$ & $72.6 \pm 1.76^{\circ} \mathrm{C}$ & NS \\
\hline Ct values $($ mean $\pm \mathrm{SD})$ & $30.45 \pm 3.43$ & $30.5 \pm 3.3$ & NS \\
\hline Conc. (median, IQR) & $\log _{10} 6.37(5.65-7.12)$ & $\log _{10} 5.81(4.26-6.65)$ & 0.046 \\
\hline Diarrhoea & $41 / 50(82 \%)$ & $16 / 19(84 \%)$ & 1.00 \\
\hline Duration of diarrhoea (median, IQR) & $19,1-45$ & $16,3-60$ & 0.89 \\
\hline Number of episodes (mean, SD) & $5 \pm 3.7$ & $5 \pm 2.8$ & 0.45 \\
\hline Fever & $23 / 50(46 \%)$ & $10 / 19(52.6 \%)$ & 0.77 \\
\hline Nausea/vomiting & $29 / 50(58 \%)$ & $5 / 19(26 \%)$ & 0.032 \\
\hline Abdominal pain & $22 / 50(44 \%)$ & $7 / 19(37 \%)$ & 0.95 \\
\hline
\end{tabular}

(SD: Standard deviation, IQR: interquartile range, NS: not significant and Ct: cycle threshold, Conc.: Equivalent oocyst concentration (parasite load)).

who more often received either double or single immunosuppressants $(41 / 43,95.4 \%$ versus $2 / 43,4.6 \%$ versus $0 / 43$; $P=0.013)$. Mycophenolate mofetil (MMF), Wysolone, and Tacrolimus were used in patients both with and without cryptosporidiosis $(17 / 43,39.5 \%$ versus $30 / 80,37.5 \%$; $P=$ $0.85)$. History of antiretroviral treatment was reported more often by patients without than those with cryptosporidiosis (21/59 versus $3 / 29, P=0.012$ ).

3.2. Genetic Characterization of Cryptosporidium spp. Cryptosporidium hominis, Cryptosporidium parvum, and mixed infection were detected in 50/71 (70.4\%), 19/71 (26.8\%), and 2/71 (2.8\%) immunocompromised patients, respectively. C. hominis, C. parvum, and mixed infection were detected among 20/28 (71.5\%), 7/28 (25\%), and 1/28 (3.5\%) HIV positive patients and $30 / 43(69.8 \%), 12 / 43(28 \%)$, and $1 / 43$ (2.2\%) RT recipients, respectively. C. hominis showed an average peak at $74.8 \pm 1.64^{\circ} \mathrm{C}$ while $C$. parvum was at
$72.6 \pm 1.76^{\circ} \mathrm{C}$, by MCA (Figures 4 and 5). Only one microscopically negative sample was positive for $C$. hominis, which was also confirmed by sequencing. The GenBank accession numbers of submitted sequences are BankIt1855902 Seq1, KT735247, BankIt1856029 Seq2, KT735248, BankIt1856031 Seq3, KT735249, BankIt1856033 Seq4, KT735250, BankIt1856035 Seq5, KT735251, BankIt1860090 Seq1, KT831947, BankIt1860090 Seq2, KT831948, BankIt1860090 Seq3, KT831949, BankIt1860090 Seq4, KT831950, and BankIt1860090 Seq5, KT831951.

3.3. Relationship between the Nature, Severity, and Duration of the Symptoms and Different Species. The demographic, laboratory, and clinical parameters of the patients infected with Cryptosporidium hominis and C. parvum are shown in Table 2. Patients with $C$. hominis infection more often had nausea and/or vomiting and increased oocyst load (denoted by equivalent concentration of oocysts in the stool samples) 


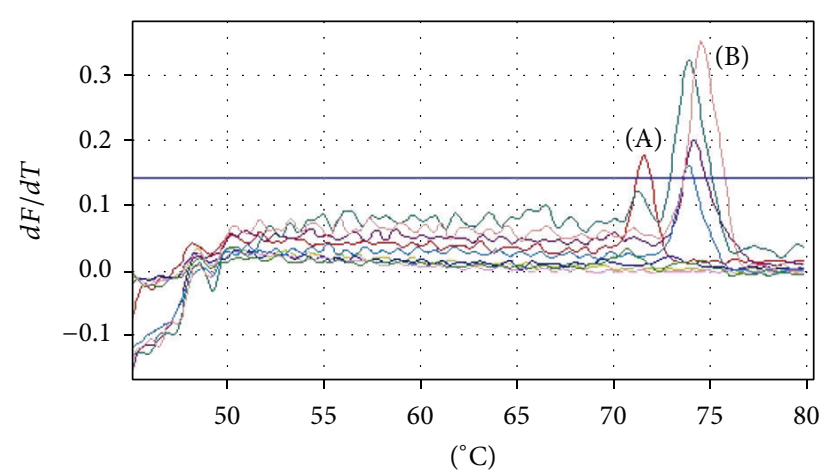

(a)

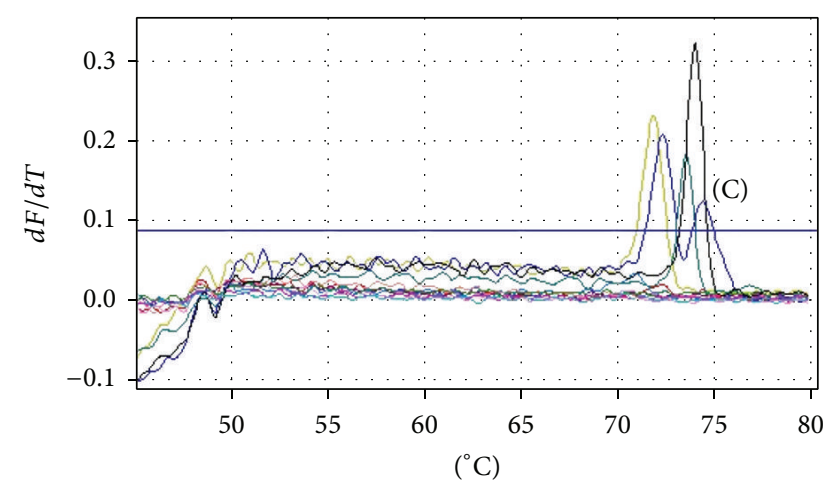

(c)

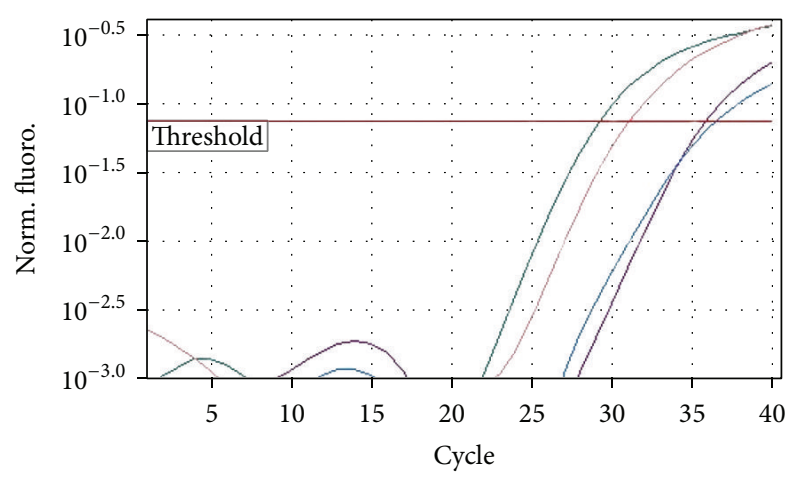

(b)

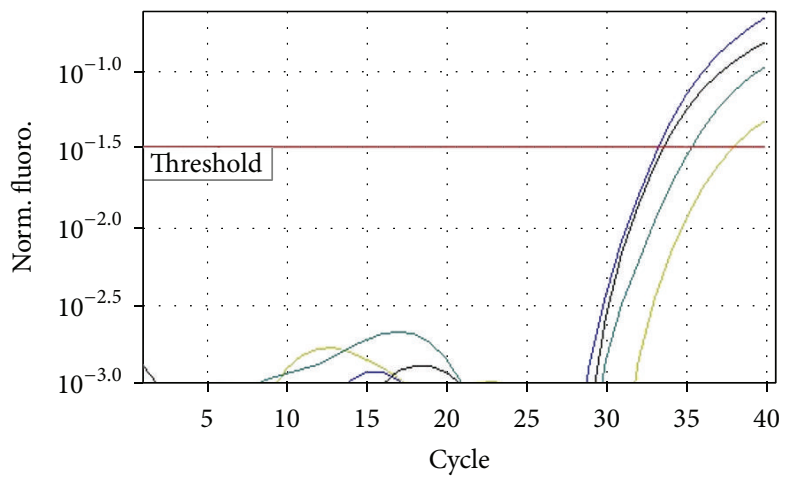

(d)

Figure 5: (a) and (c) Representative melting curves peaks; (b) and (d) respective amplification curves of samples; (A) melting curve peaks for samples positive for C. parvum (mean peak value: $72.6 \pm 1.76^{\circ} \mathrm{C}$ ); (B) melting curve peaks for samples positive for $C$. hominis (mean peak value: $\left.74.8 \pm 1.64^{\circ} \mathrm{C}\right)$; (C) melting curve peaks for samples positive for mixed infections with both C. hominis and C. parvum.

compared to patients infected with $C$. parvum $(P<0.05$; Table 2). However, fever, abdominal pain, frequency, and duration of diarrhoea were comparable between patients with C. hominis and C. parvum infection (Table 2).

3.4. Relationship between the Nature, Severity, and Duration of the Symptoms and Parasite Load. The median load of oocysts of Cryptosporidium spp. in patients with HIV infection and those with RT was comparable $\left(\log _{10} 5.65\right.$ IQR (4.73-6.89) versus $\log _{10} 6.37 \mathrm{IQR}$ (5.81-6.79), $P=\mathrm{ns}$ ). Patients having diarrhoea had higher copy number (or equivalent oocyst concentration) of Cryptosporidium than those without $\left(\log _{10}\right.$ 6.37 IQR (5.8-7.05) versus $\log _{10} 4.96 \mathrm{IQR}$ (3.92-6.06), $P=$ $0.03)$ ).

\section{Discussion}

In the current study, we found that (a) C. hominis and $C$. parvum were the only two Cryptosporidium spp. detected in immunocompromised patients, (b) cryptosporidiosis was more commonly associated with diarrhoea, increased stool frequency, and watery stool, (c) C. hominis infection was more frequently associated with nausea and/or vomiting and increased oocyst load than C. parvum, and (d) patients with diarrhoea had higher copy number (or equivalent oocyst concentration) of Cryptosporidium spp. than those without.
In the present study, C. hominis and C. parvum were the only two Cryptosporidium spp. detected in immunocompromised patients. To date, genotyping of Cryptosporidium spp. has been done mostly on HIV-infected patients. There are scanty data on genotyping of Cryptosporidium spp. among RT recipients. In studies on HIV-infected patients from South Africa [27], North America [28, 29], South America [7, 30], and Europe [31], C. hominis was the most prevalent species. However, in a few other studies, C. parvum was found to be more prevalent than C. hominis [32-35]. Studies from India also revealed $C$. hominis to be the most prevalent species infecting HIV-infected patients [36, 37]. A recent study from northern India reported two of three Cryptosporidium isolates from RT recipients to be $C$. hominis and one C. parvum by PCR-RFLP for small subunit (SSU) rRNA gene [38]. This indicates that human is the major source of transmission of the infection. To the best of our knowledge, the present study is perhaps the only one from India, which used real-time PCR for detection and genetic characterization of Cryptosporidium spp.

In this study qPCR detected Cryptosporidium in one sample that was missed by microscopy. The load of oocysts in this sample was comparatively lower than the rest. Hence, stool microscopy done by an expert is as good as qPCR for detection of Cryptosporidium. However, qPCR is useful when oocyst load is less. In addition, species identification, 
which may have clinical implications, can be done by qPCR and is not possible by microscopy $[36,39]$. qPCR has the advantage of real-time detection of PCR amplicons omitting the requirement of restriction digestion or sequence analysis for genotyping.

The current study shows that CD4 count was less in HIV patients with Cryptosporidium infection than without. It has been well documented in previous studies that patients having lower CD4 count are at higher risk of cryptosporidiosis. Chronic cryptosporidiosis generally occurs in patients with CD4 counts below 200 cells/cumm [18], and patients with CD4 count below 50 cells/cumm suffer from severe infections [3]. In fact, several studies have documented a correlation between CD4 count $<200$ cells/cumm and symptomatic cryptosporidiosis, in HIV patients [11, 17]. However, such studies are scanty in RT recipients. In our study, CD4 count among RT patients was not as low as that in HIV positive patients with cryptosporidiosis, suggesting that depletion of immune cells and factors other than CD4 count is responsible for susceptibility to cryptosporidiosis in RT patients. Subgroup analysis revealed neutrophil count tended to be lower in Cryptosporidium infected RT patients than in HIV patients. Low neutrophil count of RT patients might be attributed to some immune-suppressive drugs as well. Thus, not only immune restoration in the form of HAART therapy, but also management of immune-suppressive therapy may help in clearance of the parasite, in immunocompromised hosts.

In this study, the RT recipients with cryptosporidiosis were given mostly triple immunosuppressive drugs than double and single immunosuppressants. The combination of mycophenolate mofetil (MMF), Wysolone, and Tacrolimus drugs was mostly used in both patient and control groups. In a study from Pakistan, the immunosuppressive drugs administered to RT recipients having cryptosporidiosis comprised of cyclosporine/FK506, azathioprine/mycophenolate mofetil (MMF), and steroids (Prednisolone/Wysolone) [40]. In another study cyclosporin A has been used in infected RT recipients [41]. Till date no association of Cryptosporidium infection has been shown with any immunosuppressive drug. In fact, there are scanty data on cryptosporidiosis in RT recipients. Large-scale follow-up studies, explaining the type and dose of immunosuppressive agents and their management in Cryptosporidium infected RT recipients, could clarify this issue further.

In the present study, C. hominis was associated with frequent nausea and/or vomiting and increased oocyst load compared to C. parvum. Thus, infection caused by C. hominis was more severe than C. parvum infection. This is in accordance with the previous studies from Peru, which showed that C. hominis was associated with diarrhea, nausea, vomiting, general malaise, and increased oocyst shedding intensity and duration. In contrast, zoonotic isolates like C. parvum were associated with diarrhea only [7]. In a study from United Kingdom, duration of $C$. parvum infection was significantly lower than that of $C$. hominis $(F=8.312, P=0.005)$ [14]. Also, C. hominis was reported to cause more severe infection than C. parvum [14]. It has been mentioned in this study that $C$. hominis being a "specialist," particularly infecting the human host, show more virulent characteristics than a "generalist" like C. parvum. From Brazil, children with $C$. hominis infection have been reported to shed significantly more oocysts in stool [42]. Similarly in a study on children from India, C. hominis infection was associated with a greater severity of diarrhea [16]. In contrast, in a study from India on HIV positive patients, persons infected with $C$. parvum and other zoonotic species tended to have fever more frequently than those infected with C. hominis [11]. It is suggested that immunodeficiency is responsible for alteration of host susceptibility to the Cryptosporidium species that are normally noninfectious to humans [11].

The present study has a few limitations. The study does not involve follow-up of the patients. Follow-up studies on the same will determine the actual epidemiology of the infection and heterogeneity of clinical manifestations. Our findings, however, add some new information to the existing knowledge.

In conclusion, Cryptosporidium spp. is a common cause of diarrhoea in renal transplant recipients, as in HIV positive patients. Hence, clinicians should not overlook the possibility of occurrence of cryptosporidiosis in these patients. $C$. hominis is the most common Cryptosporidium spp. detected in both HIV and RT patients, suggesting that anthroponotic mode of transmission of the parasite is dominant in immunocompromised patients, particularly in northern India. Real-time PCR is an important and time-effective tool for diagnosis of Cryptosporidium spp. as well as its genetic characterization.

\section{Conflict of Interests}

The authors declare that there is no conflict of interests regarding the publication of this paper.

\section{Acknowledgments}

Ujjala Ghoshal acknowledges The Department of Biotechnology (DBT), New Delhi, India (Reference DBT SAN no. 102/IFD/SAN 1839/2008-09), for providing financial assistance for conducting this study. Asmita Dey is also thankful to The University Grants Commission (UGC), New Delhi, for granting her fellowship.

\section{References}

[1] J. K. P. Kwaga, J. U. Umoh, and M. B. Odoba, "Cryptosporidium infections in humans with gastroenteritis in Zaria, Nigeria," Epidemiology and Infection, vol. 101, no. 1, pp. 93-97, 1988.

[2] W. L. Current, "Cryptosporidiosis," Journal of the American Veterinary Medical Association, vol. 187, no. 12, pp. 1334-1338, 1985.

[3] P. R. Hunter and G. Nichols, "Epidemiology and clinical features of Cryptosporidium infection in immunocompromised patients," Clinical Microbiology Reviews, vol. 15, no. 1, pp. 145$154,2002$.

[4] S. S. R. Ajjampur, P. Sankaran, and G. Kang, "Cryptosporidium species in HIV-infected individuals in India: an overview," 
National Medical Journal of India, vol. 21, no. 4, pp. 178-184, 2008.

[5] U. Z. Ok, M. Cirit, A. Uner et al., "Cryptosporidiosis and blastocystosis in renal transplant recipients," Nephron, vol. 75, no. 2, pp. 171-174, 1997.

[6] F. Bandin, T. Kwon, M.-D. Linas et al., "Cryptosporidiosis in paediatric renal transplantation," Pediatric Nephrology, vol. 24, no. 11, pp. 2245-2255, 2009.

[7] V. A. Cama, C. Bern, J. Roberts et al., "Cryptosporidium species and subtypes and clinical manifestations in children, Peru," Emerging Infectious Diseases, vol. 14, no. 10, pp. 1567-1574, 2008.

[8] W. Gatei, C. N. Wamae, C. Mbae et al., "Cryptosporidiosis: prevalence, genotype analysis, and symptoms associated with infections in children in Kenya," The American Journal of Tropical Medicine and Hygiene, vol. 75, no. 1, pp. 78-82, 2006.

[9] S. Coupe, C. Sarfati, S. Hamane, and F. Derouin, "Detection of Cryptosporidium and identification to the species level by nested PCR and restriction fragment length polymorphism," Journal of Clinical Microbiology, vol. 43, no. 3, pp. 1017-1023, 2005.

[10] F. Spano, L. Putignani, J. McLauchlin, D. P. Casemore, and A. Crisanti, "PCR-RFLP analysis of the Cryptosporidium oocyst wall protein (COWP) gene discriminates between C. wrairi and C. parvum, and between C. parvum isolates of human and animal origin," FEMS Microbiology Letters, vol. 150, no. 2, pp. 209-217, 1997.

[11] S. S. Rao Ajjampur, J. R. Asirvatham, D. Muthusamy et al., "Clinical features \& risk factors associated with cryptosporidiosis in HIV infected adults in India," Indian Journal of Medical Research, vol. 126, no. 6, pp. 553-557, 2007.

[12] R. M. Chalmers, K. Elwin, S. J. Hadfield, and G. Robinson, "Sporadic human cryptosporidiosis caused by Cryptosporidium cuniculus, United Kingdom, 2007-2008," Emerging Infectious Diseases, vol. 17, no. 3, pp. 536-538, 2011.

[13] K. Elwin, S. J. Hadfield, G. Robinson, N. D. Crouch, and R. M. Chalmers, "Cryptosporidium viatorum n. sp. (Apicomplexa: Cryptosporidiidae) among travellers returning to Great Britain from the Indian subcontinent, 2007-2011," International Journal for Parasitology, vol. 42, no. 7, pp. 675-682, 2012.

[14] P. R. Hunter, S. Hughes, S. Woodhouse et al., "Sporadic cryptosporidiosis case-control study with genotyping," Emerging Infectious Diseases, vol. 10, no. 7, pp. 1241-1249, 2004.

[15] P. R. Hunter, S. Hughes, S. Woodhouse et al., "Health sequelae of human cryptosporidiosis in immunocompetent patients," Clinical Infectious Diseases, vol. 39, no. 4, pp. 504-510, 2004.

[16] S. S. R. Ajjampur, B. P. Gladstone, D. Selvapandian, J. P. Muliyil, H. Ward, and G. Kang, "Molecular and spatial epidemiology of cryptosporidiosis in children in a semiurban community in South India," Journal of Clinical Microbiology, vol. 45, no. 3, pp. 915-920, 2007.

[17] S. V. Kulkarni, R. Kairon, S. S. Sane et al., "Opportunistic parasitic infections in HIV/AIDS patients presenting with diarrhoea by the level of immunesuppression," Indian Journal of Medical Research, vol. 130, no. 1, pp. 63-66, 2009.

[18] U. Ghoshal and A. Dey, "Human cryptosporidiosis and drinking water: looking beyond HIV," in Water and Health, pp. 201218, Springer, New Delhi, India, 2014.

[19] J. P. Rasmussen, C. P. Saint, and P. T. Monis, "Use of DNA melting simulation software for in silico diagnostic assay design: targeting regions with complex melting curves and confirmation by real-time PCR using intercalating dyes," $B M C$ Bioinformatics, vol. 8, article 107, 2007.
[20] National AIDS Control Organization (NACO), Guidelines for HIV Testing, 2007.

[21] World Medical Association, "World Medical Association Declaration of Helsinki: ethical principles for medical research involving human subjects," The Journal of the American Medical Association, vol. 310, no. 20, pp. 2191-2194, 2013.

[22] L. S. Garcia, Diagnostic Medical Parasitology, American Society for Microbiology Press, Washington, DC, USA, 4th edition, 2001.

[23] M. Cheesbrough, District Laboratory Practice in Tropical Countries, Cambridge University Press, Cambridge, UK, 2nd edition, 2006.

[24] R. H. Soliman and A. A. Othman, "Evaluation of DNA melting curve analysis real-time PCR for detection and differentiation of Cryptosporidium species," Parasitologists United Journal, vol. 2, no. 1, pp. 47-54, 2009.

[25] J. Minarovičová, E. Kaclíková, K. Krascsenicsová, P. Siekel, and T. Kuchta, "A single-tube nested real-time polymerase chain reaction for sensitive contained detection of Cryptosporidium parvum," Letters in Applied Microbiology, vol. 49, no. 5, pp. 568572, 2009.

[26] Z. Wu, I. Nagano, A. Matsuo et al., "Specific PCR primers for Cryptosporidium parvum with extra high sensitivity," Molecular and Cellular Probes, vol. 14, no. 1, pp. 33-39, 2000.

[27] C. Sarfati, A. Bourgeois, J. Menotti et al., "Prevalence of intestinal parasites including Microsporidia in human immunodeficiency virus-infected adults in Cameroon: a cross-sectional study," American Journal of Tropical Medicine and Hygiene, vol. 74, no. 1, pp. 162-164, 2006.

[28] I. M. Sulaiman, L. Xiao, C. Yang et al., "Differentiating human from animal isolates of Cryptosporidium parvum," Emerging Infectious Diseases, vol. 4, no. 4, pp. 681-685, 1998.

[29] W. Gatei, D. Barrett, J. F. Lindo, D. Eldemire-Shearer, V. Cama, and L. Xiao, "Unique Cryptosporidium population in HIVinfected persons, Jamaica," Emerging Infectious Diseases, vol. 14, no. 5, pp. 841-843, 2008.

[30] V. A. Cama, C. Bern, I. M. Sulaiman et al., "Cryptosporidium species and genotypes in HIV-positive patients in Lima, Peru," Journal of Eukaryotic Microbiology, vol. 50, supplement, pp. 531533, 2003.

[31] M. T. Llorente, A. Clavel, M. P. Goñi et al., "Genetic characterization of Cryptosporidium species from humans in Spain," Parasitology International, vol. 56, no. 3, pp. 201-205, 2007.

[32] A. Iqbal, Y. A. L. Lim, J. Surin, and B. L. H. Sim, "High diversity of Cryptosporidium subgenotypes identified in Malaysian HIV/AIDS individuals targeting gp60 gene," PLoS ONE, vol. 7, no. 2, Article ID e31139, 2012.

[33] K. Guyot, A. Follet-Dumoulin, E. Lelièvre et al., "Molecular characterization of Cryptosporidium isolates obtained from humans in France," Journal of Clinical Microbiology, vol. 39, no. 10, pp. 3472-3480, 2001.

[34] W. Gatei, J. Greensill, R. W. Ashford et al., "Molecular analysis of the 18S rRNA gene of Cryptosporidium parasites from patients with or without human immunodeficiency virus infections living in Kenya, Malawi, Brazil, the United Kingdom, and Vietnam," Journal of Clinical Microbiology, vol. 41, no. 4, pp. 1458-1462, 2003.

[35] A. R. Meamar, M. Rezaian, S. Rezaie et al., "SSU-rRNA gene analysis of Cryptosporidium spp. in HIV positive and negative patients," Iranian Journal of Public Health, vol. 35, no. 4, pp. 1-7, 2006. 
[36] D. Muthusamy, S. S. Rao, S. Ramani et al., "Multilocus genotyping of Cryptosporidium sp. isolates from human immunodeficiency virus-infected individuals in South India," Journal of Clinical Microbiology, vol. 44, no. 2, pp. 632-634, 2006.

[37] K. K. Dwivedi, G. Prasad, S. Saini, S. Mahajan, S. Lal, and U. K. Baveja, "Enteric opportunistic parasites among HIV infected individuals: associated risk factors and immune status," Japanese Journal of Infectious Diseases, vol. 60, no. 2-3, pp. 76-81, 2007.

[38] P. Sharma, A. Sharma, R. Sehgal, N. Malla, and S. Khurana, "Genetic diversity of Cryptosporidium isolates from patients in North India," International Journal of Infectious Diseases, vol. 17, no. 8, pp. e601-e605, 2013.

[39] S. Tanriverdi, A. Tanyeli, F. Başlamişli et al., "Detection and genotyping of oocysts of Cryptosporidium parvum by realtime PCR and melting curve analysis," Journal of Clinical Microbiology, vol. 40, no. 9, pp. 3237-3244, 2002.

[40] K. Raja, Z. Abbas, S. M. Hassan, N. H. Luck, T. Aziz, and M. Mubarak, "Prevalence of cryptosporidiosis in renal transplant recipients presenting with acute diarrhea at a single center in Pakistan," Journal of Nephropathology, vol. 3, no. 4, pp. 127-131, 2014.

[41] A. B. Dehkordy, A. Rafiei, S. M. Alavi, and S. M. Latifi, "Prevalence of Cryptosporidium infection in immunocompromised patients, in South-West of Iran, 2009-10," Iranian Journal of Parasitology, vol. 5, no. 4, pp. 42-47, 2010.

[42] M. Burdese, V. Veglio, V. Consiglio et al., "A dance teacher with kidney-pancreas transplant and diarrhoea: what is the cause?" Nephrology Dialysis Transplantation, vol. 20, no. 8, pp. 17591761, 2005. 


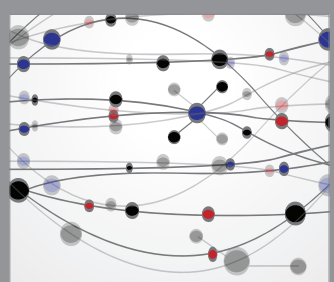

The Scientific World Journal
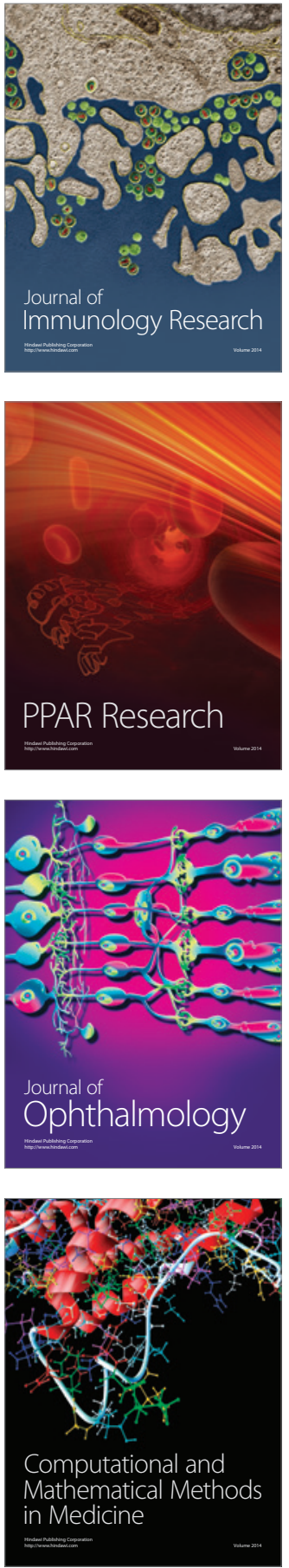

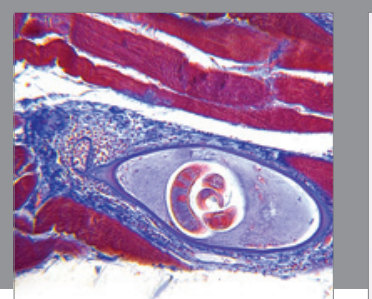

Gastroenterology Research and Practice

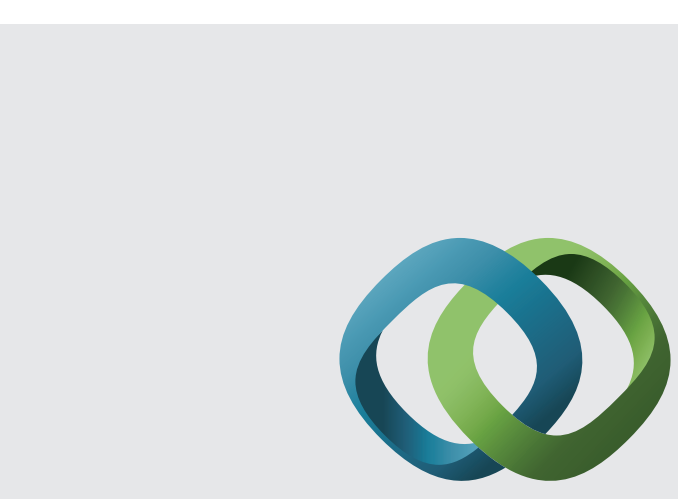

\section{Hindawi}

Submit your manuscripts at

http://www.hindawi.com
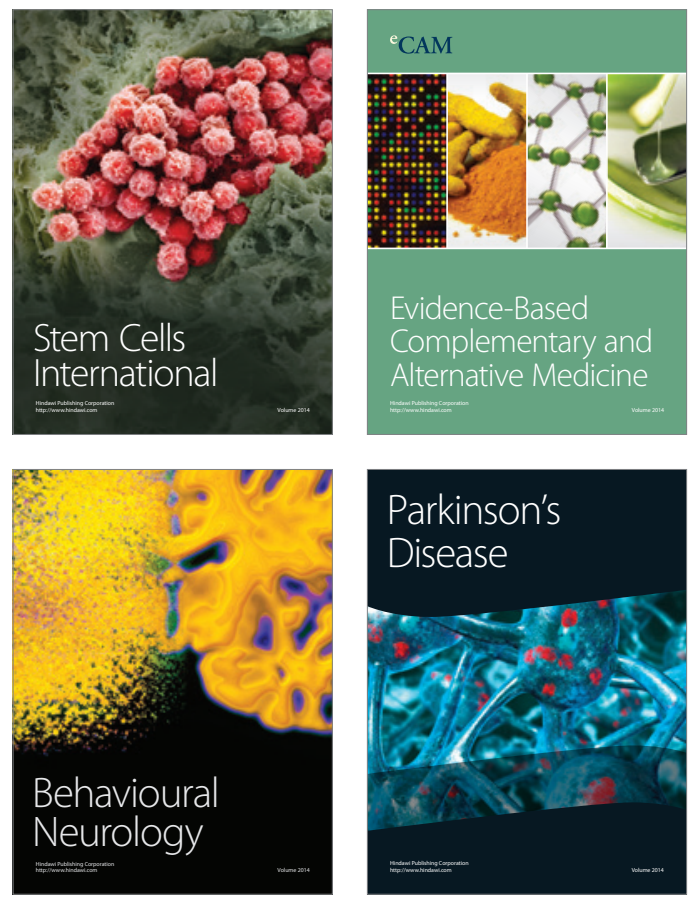
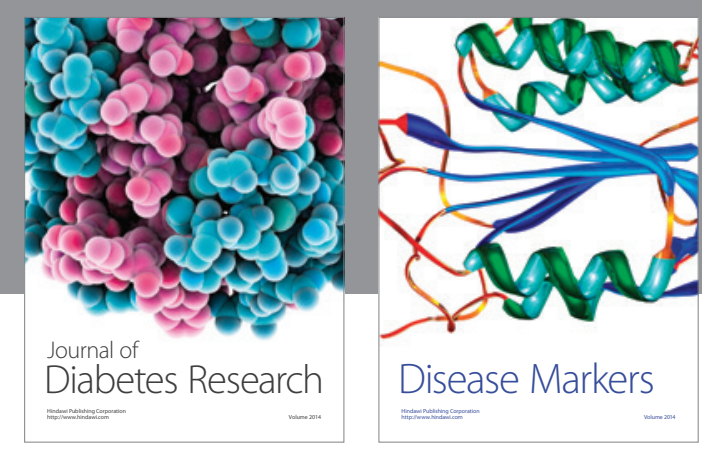

Disease Markers
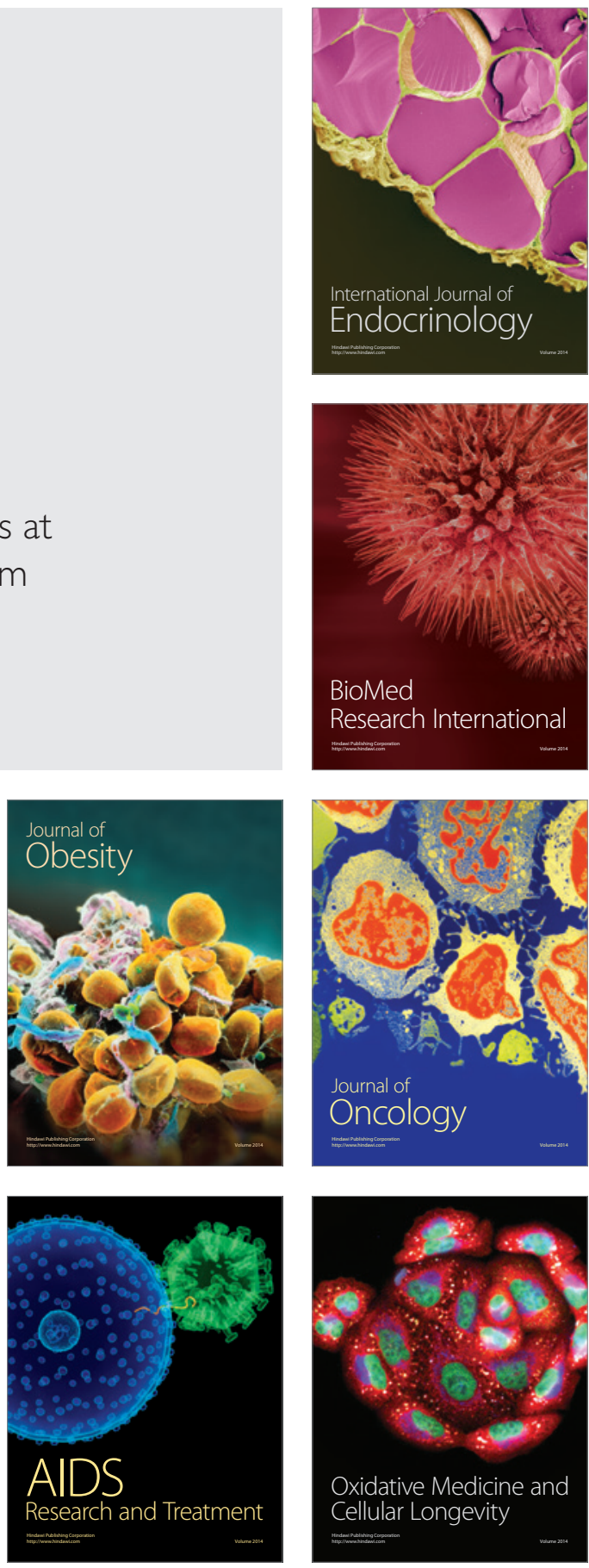